\title{
Boilerplate being tested for clinical trials agreements
}

$\mathrm{T}$ he Canadian Institutes of Health Research (CIHR) is hoping to slash startup times for Phase II and III clinical trials in Canada by introducing a standard template for agreements between sponsors and researchers.

As part of a six-month pilot which started in October, the federal granting council began urging members of Canada's Research-Based Pharmaceutical Companies (Rx\&D) and the Association of Canadian Academic Healthcare Organizations to use a model "clinical trial template agreement" in negotiations, rather than waste time and money crafting contracts from scratch (www.cihr-irsc.gc.ca/e/4 4186.html).

The template boils down the relationship and obligations of all parties and provides a benchmark for negotiating typi-

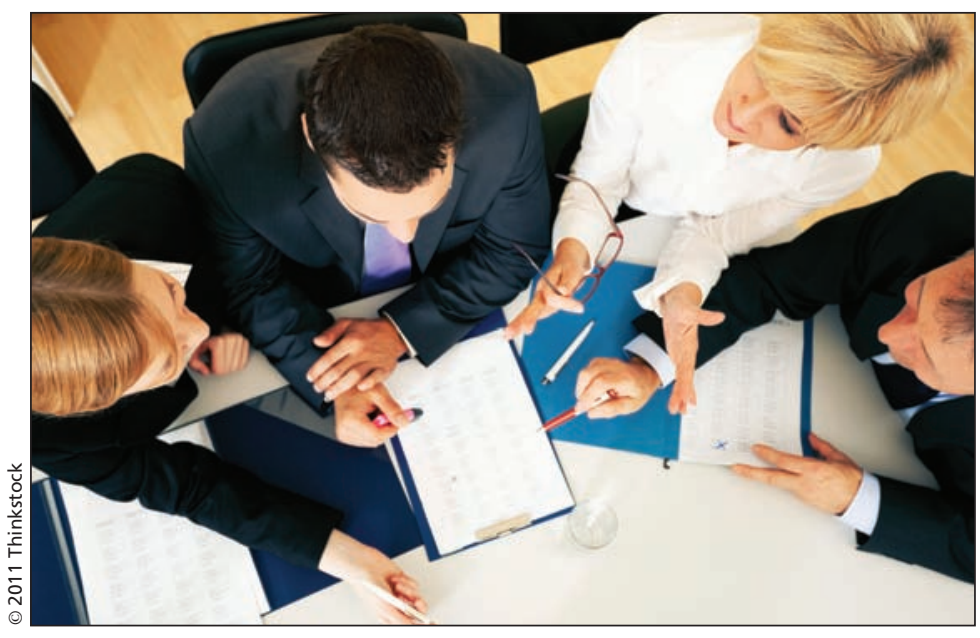

Squabbling over clinical trial agreements represents a barrier to investment, according to Canada's Research-Based Pharmaceutical Companies (Rx\&D). seen increases in clinical research. "Canada is the most expensive country [in which to conduct trials], one of the slowest to initiate trials and not very efficient in terms of [patient] recruitment."

The consequence of Canada's flagging performance is a loss of $\$ 300$ million to $\$ 500$ million a year in the country's research portfolio, Laberge
Archer, convenor of the chairs' group of the Association of UK University Hospitals, said in a press release (www.dh.gov.uk/en/MediaCentre/Press releases/DH_124576).

About $75 \%$ of the content in individually crafted clinical trial agreements is virtually identical, while a further $10 \%$ is easy to harmonize, according to an internal report on 19 company agreements undertaken by Rx\&D, Laberge says.

Simplifying the contracting process will "bring us one step closer towards increasing the attractiveness of Canada clinical trial sites as preferred partners internationally for clinical trials, and ultimately continue to bring human, social and economic benefits to all," Brimacombe, CIHR President Dr. Alain Beaudet and Rx\&D President Russell Williams argued in a press release (www.cihr-irsc .gc.ca/e/44203.html). estimates. "We have lost our competitive edge."

International peers such as the United Kingdom have been using template agreements for the past decade. The UK's National Institute of Health Research states in guidance on the use of such templates that they have been widely recognized as being "fair, evenhanded and acceptable to [all] parties," while "their availability usually avoids the lengthy and potentially costly legal review and negotiation that is often required by the use of individual companies' documents" (www.nihr.ac.uk /files/mICRA\%20Guidance.pdf).

Template agreements have also served to level the playing field in clinical trial negotiations for academic and public sector organizations, which often don't have the legal resources to "enter confidently into collaborative arrangements with industry," Dr. Mary
Bolstering clinical trial investment
els in Canada will provide relief to the health care system, as treatment of patients enrolled in trials is covered by sponsors, adds Laberge.

What remains to be seen is whether a single template agreement can truly be one-size-fits-all, says Brimacombe. "We'll have to see how generalizable this is and I'm hoping that's one of the issues that will become clearer as we go through the pilot process."

Participants in the pilot are free to tweak the template but CIHR is asking participants to limit changes to "only what is absolutely necessary" and report back on what items were changed. That data will be used to inform revisions to the template.

The pilot will run from October 2011 to April 2012. — Lauren Vogel, CMAJ

CMAJ 2011. DOI:10.1503/cmaj.109-4016 